\title{
Severe obesity in children: prevalence, persistence and relation to hypertension
}

\author{
Joan C Lo ${ }^{1,2^{*}}$, Malini Chandra ${ }^{1}$, Alan Sinaiko ${ }^{3}$, Stephen R Daniels ${ }^{4}$, Ronald J Prineas ${ }^{5}$, Benjamin Maring ${ }^{2}$, \\ Emily D Parker ${ }^{6}$, Nancy E Sherwood ${ }^{6}$, Matthew F Daley ${ }^{7}$, Elyse O Kharbanda ${ }^{6}$, Kenneth F Adams ${ }^{6}$, David J Magid ${ }^{4,7}$, \\ Patrick J O'Connor ${ }^{6}$ and Louise C Greenspan ${ }^{8}$
}

\begin{abstract}
Background: Newer approaches for classifying gradations of pediatric obesity by level of body mass index (BMI) percentage above the $95^{\text {th }}$ percentile have recently been recommended in the management and tracking of obese children. Examining the prevalence and persistence of severe obesity using such methods along with the associations with other cardiovascular risk factors such as hypertension is important for characterizing the clinical significance of severe obesity classification methods.
\end{abstract}

Methods: This retrospective study was conducted in an integrated healthcare delivery system to characterize obesity and obesity severity in children and adolescents by level of body mass index (BMI) percentage above the $95^{\text {th }}$ BMI percentile, to examine tracking of obesity status over 2-3 years, and to examine associations with blood pressure. Moderate obesity was defined by BMI 100-119\% of the $95^{\text {th }}$ percentile and severe obesity by BMI $\geq 120 \% \times 95^{\text {th }}$ percentile. Hypertension was defined by 3 consecutive blood pressures $\geq 95^{\text {th }}$ percentile (for age, sex and height) on separate days and was examined in association with obesity severity.

Results: Among 117,618 children aged 6-17 years with measured blood pressure and BMl at a well-child visit during 2007-2010, the prevalence of obesity was 17.9\% overall and was highest among Hispanics (28.9\%) and blacks (20.5\%) for boys, and blacks (23.3\%) and Hispanics (21.5\%) for girls. Severe obesity prevalence was 5.6\% overall and was highest in 12-17 year old Hispanic boys (10.6\%) and black girls (9.5\%). Subsequent BMl obtained 2-3 years later also demonstrated strong tracking of severe obesity. Stratification of BMI by percentage above the $95^{\text {th }}$ BMl percentile was associated with a graded increase in the risk of hypertension, with severe obesity contributing to a 2.7-fold greater odds of hypertension compared to moderate obesity.

Conclusion: Severe obesity was found in 5.6\% of this community-based pediatric population, varied by gender and race/ethnicity (highest among Hispanics and blacks) and showed strong evidence for persistence over several years. Increasing gradation of obesity was associated with higher risk for hypertension, with a nearly three-fold increased risk when comparing severe to moderate obesity, underscoring the heightened health risk associated with severe obesity in children and adolescents.

Keywords: Obesity, Children, Adolescents, Blood pressure

\footnotetext{
* Correspondence: Joan.C.Lo@kp.org

${ }^{1}$ Division of Research, Kaiser Permanente Northern California, 2000 Broadway,

Oakland, CA 94612, USA

${ }^{2}$ Department of Medicine, Kaiser Permanente Oakland Medical Center,

Oakland, CA, USA

Full list of author information is available at the end of the article
} 


\section{Background}

Data from U.S. population surveys demonstrate a significant increase in obesity prevalence among children age $2-19$ years old, from $5.5 \%$ in $1976-1980$ [1] to $16.9 \%$ in 2007-2010 [1,2], with obesity defined as body mass index $(\mathrm{BMI}) \geq 95^{\text {th }}$ percentile using the Centers for Disease Control and Prevention (CDC) 2000 growth charts [3]. As obesity rates have climbed in all age groups [4-7], the prevalence of severe obesity has also risen, increasing from $1.1 \%$ to $5.1 \%$ in boys and $1.3 \%$ to $4.7 \%$ in girls from 1976-2006 [7]. Historically, severe obesity in children has been described in broad terms, with fewer studies examining gradations of obesity severity in relation to potentially adverse secondary complications. Methods for classifying extremely high BMI have evolved in the past decade, related in part to the limited utility of BMI percentiles and $\mathrm{Z}$ scores where contraction of values occurs at the upper range [8]. As an alternative, expressing BMI as a percentage of the $95^{\text {th }}$ BMI percentile has been recommended for characterizing and tracking children with high BMI [9-11], where a threshold of BMI $\geq 120 \%$ of the $95^{\text {th }}$ percentile has been used to define severe obesity [7,9-12]. New growth charts with additional growth curves representing higher order BMI as a percentage of the $95^{\text {th }}$ percentile have also been recently published $[10,11]$ and may allow for more precise stratification of risk among obese children.

The present study conducted in a contemporary, diverse population of children followed in routine pediatric clinical care settings was designed with three specific aims. First, we characterized obesity severity by expressing BMI as a percentage of the $95^{\text {th }}$ BMI percentile for age and sex. Second, we examined obesity status over 2-3 years follow-up, to determine tracking of both obesity and severe obesity in children and early adolescents. Third, we applied these new obesity stratification criteria to examine the association of obesity severity and hypertension as a potential indicator of the degree of cardiovascular health risk.

\section{Methods}

The Institutional Review Board at HealthPartners Institute for Education and Research approved the study with ceding of oversight authority by the KPNC Institutional Review Board. A waiver of informed consent was obtained due to the nature of the study.

Kaiser Permanente Northern California (KPNC) is a large integrated healthcare delivery system providing comprehensive care for more than three million members annually. For this study, we examined data from a large retrospective multicenter study of pediatric hypertension [13], using a subcohort that included 117,936 children aged 6-17 years receiving care within three large KPNC subregions. Data pertaining to age, height, weight and blood pressure were obtained from the electronic medical record for the first (index) well child visit with measured height, weight and blood pressure between July 1, 2007 and December 31, 2010 as previously described [13]. Data for race/ethnicity, sex and membership were obtained from administrative databases.

Height was measured by stadiometer and weight was measured on a calibrated scale as part of routine clinical care. Body mass index (BMI) was calculated as weight in kilograms divided by height in meters squared $\left(\mathrm{kg} / \mathrm{m}^{2}\right)$, with percentiles calculated from the year 2000 CDC growth charts and reference datasets [14] to classify children as normal weight or underweight (BMI $<85^{\text {th }}$ BMIfor-age percentile); overweight (BMI $85^{\text {th }}-94^{\text {th }}(94.9)$ BMI-for-age percentile); or obese (BMI $\geq 95^{\text {th }}$ BMI-forage percentile) [3,4] as previously described [13,15]. For the purposes of this study, obese children were further classified based on BMI expressed as a percentage above the $95^{\text {th }}$ BMI percentile according to age and sex $[9,11]$, with a BMI $100-119 \%$ of the $95^{\text {th }}$ percentile used to define moderate obesity and a BMI $\geq 120 \%$ of the $95^{\text {th }}$ BMI percentile used to define severe obesity $[7,9,12]$. For children aged 6-13 years, a follow-up BMI was also examined when the child was 2-3 years older (available in $73.1 \%$ of subjects, requiring a minimum of 600 days between visits; $89.5 \%$ of follow-up visits were for well child care).

To address potential BMI errors in the electronic medical record for the index visit, we first excluded those with height flagged as "biologically implausible" by the CDC program [16] and those with height $<91.4$ or $>213.4 \mathrm{~cm}$, weight $<9.1$ or $>272.2 \mathrm{~kg}$, or $\mathrm{BMI}<10$ or $>120 \mathrm{~kg} / \mathrm{m}^{2}$. Next, 540 growth charts were manually reviewed if the index anthropometric data met any of the following criteria: (1) high values of weight or BMI flagged as "biologically implausible" by the CDC program [16] (except adolescents 12-17 years old with another BMI <5\% different from the index value); (2) severely obese children with another height, weight or BMI differing by $>15-20 \%$ per year within 2 years; and (3) obese children with subsequent non-obese BMI. Review of these outlying values resulted in the exclusion of 97 children with data errors.

Blood pressure measurements were obtained using oscillometric devices as previously described [13], with levels classified according to the Fourth Report on the Diagnosis, Evaluation and Treatment of High Blood Pressure in Children and Adolescents [17]. Normal blood pressure was defined as a systolic and diastolic blood pressure $<90^{\text {th }}$ percentile, prehypertension was defined as a systolic or diastolic blood pressure between the $90^{\text {th }}$ and $<95^{\text {th }}$ percentile (or blood pressure $\geq 120$ / $80 \mathrm{mmHg}$ for adolescents) and an elevated BP in the hypertension range was defined by a systolic or diastolic 
$B P \geq 95^{\text {th }}$ percentile [17]. Among children and adolescents with an index (initial) elevated $B P \geq 95^{\text {th }}$ percentile, hypertension was classified based on two additional consecutive BP measurements $\geq 95^{\text {th }}$ percentile [17] or SBP $\geq 140$ and/or DBP $\geq 90 \mathrm{mmHg}$ for subsequent BP obtained at age $\geq 18$ years and older $(0.24 \%$ of the overall cohort) as previously described [13]. There were 730 (3.5\% of the overall cohort) who did not have follow-up $\mathrm{BP}$ to allow final BP classification.

\section{Statistical analysis}

All analyses were conducted using SAS version 9.3 (SAS Institute, Cary, NC). Means with standard deviation and medians with interquartile range for continuous variables and proportions for categorical variables were computed. Differences between subgroups and classification methods were compared using the chi-square test for categorical variables and Student's t-test for continuous variables. The trend in proportions across categories was examined using the Cochrane-Armitage test. Multivariable logistic regression was used to examine the independent relationship of obesity severity and elevated blood pressure, adjusting for differences in age, race/ethnicity and sex. These multivariable analyses, conducted in obese children, excluded 107 $(0.5 \%)$ who received treatment with blood pressure lowering medication (the majority received clonidine or guanfacine, for presumably non-hypertensive indications) in the six months prior to the index well-child visit. A p-value of

Table 1 Body mass index (BMI) classification by BMI percentile for children age 6-17 years old

\begin{tabular}{|c|c|c|c|c|c|c|}
\hline & & $\mathrm{BMI}<5^{\text {th }}$ percentile & BMI 5-84 ${ }^{\text {th }}$ percentile & BMI $85-94^{\text {th }}$ percentile & $\mathrm{BMI} \geq 95^{\text {th }}$ percentile & $\begin{array}{l}\mathrm{BMI} \geq 120 \% \text { times } \\
\text { the } 95^{\text {th }} \text { percentile }\end{array}$ \\
\hline OVERALL & 117618 & $2679(2.3 \%)$ & $73630(62.6 \%)$ & $20296(17.3 \%)$ & $21013(17.9 \%)$ & $6532(5.6 \%)$ \\
\hline \multicolumn{7}{|l|}{ Race/ethnicity } \\
\hline White & 36793 & $892(2.4 \%)$ & $24859(67.6 \%)$ & $5941(16.2 \%)$ & $5101(13.9 \%)$ & $1401(3.8 \%)$ \\
\hline Black & 10306 & $150(1.5 \%)$ & $5921(57.5 \%)$ & $1980(19.2 \%)$ & $2255(21.9 \%)$ & $853(8.3 \%)$ \\
\hline Hispanic & 30821 & $447(1.5 \%)$ & 16609 (53.9\%) & $6001(19.5 \%)$ & $7764(25.2 \%)$ & $2618(8.5 \%)$ \\
\hline Asian/PI & 24701 & $828(3.4 \%)$ & $16753(67.8 \%)$ & $3789(15.3 \%)$ & $3331(13.5 \%)$ & $873(3.5 \%)$ \\
\hline Other/unkn & 14997 & $362(2.4 \%)$ & $9488(63.3 \%)$ & $2585(17.2 \%)$ & $2562(17.1 \%)$ & $787(5.3 \%)$ \\
\hline \multicolumn{7}{|l|}{ Age group } \\
\hline $6-11$ yrs & 52567 & $1325(2.5 \%)$ & $32619(62.1 \%)$ & $8897(16.9 \%)$ & $9726(18.5 \%)$ & $2773(5.3 \%)$ \\
\hline $12-17$ yrs & 65051 & $1354(2.1 \%)$ & 41011 (63.0\%) & 11399 (17.5\%) & $11287(17.4 \%)$ & $3759(5.8 \%)$ \\
\hline BOYS & 59380 & $1432(2.4 \%)$ & $35870(60.4 \%)$ & 9924 (16.7\%) & $12154(20.5 \%)$ & 3935 (6.6\%) \\
\hline \multicolumn{7}{|l|}{ Race/ethnicity } \\
\hline White & 18488 & $503(2.7 \%)$ & $12262(66.3 \%)$ & $2843(15.4 \%)$ & $2880(15.6 \%)$ & $830(4.5 \%)$ \\
\hline Black & 5195 & $88(1.7 \%)$ & $3140(60.4 \%)$ & $902(17.4 \%)$ & $1065(20.5 \%)$ & $421(8.1 \%)$ \\
\hline Hispanic & 15507 & $230(1.5 \%)$ & 7983 (51.5\%) & 2819 (18.2\%) & 4475 (28.9\%) & $1580(10.2 \%)$ \\
\hline Asian/PI & 12661 & 417 (3.3\%) & 7967 (62.9\%) & 2049 (16.2\%) & $2228(17.6 \%)$ & $613(4.8 \%)$ \\
\hline Other/unkn & 7529 & $194(2.6 \%)$ & $4518(60.0 \%)$ & $1311(17.4 \%)$ & 1506 (20.0\%) & $491(6.5 \%)$ \\
\hline \multicolumn{7}{|l|}{ Age group } \\
\hline $6-11$ yrs & 26977 & $633(2.4 \%)$ & 16075 (59.6\%) & 4607 (17.1\%) & $5662(21.0 \%)$ & $1702(6.3 \%)$ \\
\hline $12-17$ yrs & 32403 & 799 (2.5\%) & 19795 (61.1\%) & $5317(16.4 \%)$ & $6492(20.0 \%)$ & 2233 (6.9\%) \\
\hline GIRLS & 58238 & 1247 (2.1\%) & $37760(64.8 \%)$ & $10372(17.8 \%)$ & 8859 (15.2\%) & 2597 (4.5\%) \\
\hline \multicolumn{7}{|l|}{ Race/ethnicity } \\
\hline White & 18305 & $389(2.1 \%)$ & $12597(68.8 \%)$ & $3098(16.9 \%)$ & $2221(12.1 \%)$ & $571(3.1 \%)$ \\
\hline Black & 5111 & $62(1.2 \%)$ & $2781(54.4 \%)$ & $1078(21.1 \%)$ & $1190(23.3 \%)$ & $432(8.5 \%)$ \\
\hline Hispanic & 15314 & $217(1.4 \%)$ & $8626(56.3 \%)$ & $3182(20.8 \%)$ & $3289(21.5 \%)$ & 1038 (6.8\%) \\
\hline Asian/PI & 12040 & $411(3.4 \%)$ & $8786(73.0 \%)$ & $1740(14.5 \%)$ & 1103 (9.2\%) & $260(2.2 \%)$ \\
\hline Other/unkn & 7468 & $168(2.3 \%)$ & $4970(66.6 \%)$ & $1274(17.1 \%)$ & $1056(14.1 \%)$ & 296 (4.0\%) \\
\hline \multicolumn{7}{|l|}{ Age group } \\
\hline $6-11$ yrs & 25590 & $692(2.7 \%)$ & 16544 (64.7\%) & $4290(16.8 \%)$ & 4064 (15.9\%) & $1071(4.2 \%)$ \\
\hline $12-17 y r s$ & 32648 & $555(1.7 \%)$ & 21216 (65.0\%) & 6082 (18.6\%) & 4795 (14.7\%) & 1526 (4.7\%) \\
\hline
\end{tabular}

Numbers represent row percentages; yrs= years; unkn= unknown. 
$<0.05$ was chosen as the criterion for statistical significance.

\section{Results}

The final study population consisted of 117,618 children and adolescents aged 6-17 years with measured height, weight and blood pressure at well child visits between July 1, 2007 and December 31, 2010. Half (49.5\%) were female and $55.3 \%$ were age $12-17$ years old. There was substantial racial and ethnic diversity, with $31.3 \%$ white, 8.8\% black, 26.2\% Hispanic, 21.0\% Asian/Pacific Islander (PI) and the remainder of other or unknown race/ethnicity $(12.8 \%)$. Overall, $17.9 \%$ met criteria for obesity defined by BMI $\geq 95^{\text {th }}$ percentile, with a greater proportion among boys versus girls, and slightly greater among younger versus older age group (Table 1). Differences were also seen by race/ethnicity. Among boys, the highest prevalence of obesity was seen in Hispanics (28.9\%), followed by blacks (20.5\%), Asians (17.6\%) and whites (15.6\%, $\mathrm{p}<0.001$ for all comparisons). Among girls, the highest prevalence was seen in blacks $(23.3 \%)$ followed by Hispanics (21.5\%), whites (12.1\%) and Asians (9.2\%, $\mathrm{p}<0.01$ for all comparisons). Figure 1 further compares prevalence findings by race/ethnicity within each age-sex subgroup. Overall, $5.6 \%$ of the cohort had severe obesity defined by BMI $\geq 120 \%$ of the $95^{\text {th }}$ BMI percentile, with a greater proportion among boys compared to girls ( $6.6 \%$ vs. $4.5 \%, \mathrm{p}<0.001)$. The prevalence of severe obesity also varied by race/ethnicity, ranging from $3.5 \%$ in Asians and $3.8 \%$ in whites to $8.3 \%$ in blacks and $8.5 \%$ in Hispanics ( $<<0.001$ for Asians and whites vs. blacks and
Hispanics). When examined across age-sex subgroups (Figure 1), the prevalence of severe obesity was highest in Hispanic boys aged 6-11 (9.7\%) and 12-17 (10.6\%) years and Black girls aged $12-17(9.5 \%)$ years. In multivariable analyses, increasing age, male sex (adjusted odds ratio OR 1.5, 95\% confidence interval CI 1.5-1.6), Hispanic ethnicity (OR 2.4, 95\% CI 2.2-2.5) and black race (OR 2.3, 95\% CI 2.1-2.5) were independent predictors of severe obesity.

Table 2 shows the proportion of children within each BMI percentage category above the $95^{\text {th }}$ percentile, by age and sex. For the 21,013 obese children (BMI $\geq 95^{\text {th }}$ percentile), nearly one third were severely obese (BMI $\geq 120 \%$ of the $95^{\text {th }}$ percentile). Half of severely obese youth had BMI $120-129 \%$ of the $95^{\text {th }}$ percentile and the remainder were evenly distributed across BMI 130-139\% and BMI $\geq 140 \%$ of the $95^{\text {th }}$ percentile. The remaining two thirds of obese children met criteria for moderate obesity (BMI $100-119 \%$ of the $95^{\text {th }}$ percentile). For both boys and girls with $\mathrm{BMI} \geq 95^{\text {th }}$ percentile, a greater proportion of older compared to younger children met criteria for severe obesity $(\mathrm{p}<0.05$ comparing age $6-11$ vs. 12-17 years old).

There was a strong tendency for obese children to remain in an obese BMI category over the follow-up period of this study. Follow-up analyses conducted using data from 80,697 children age 6-13 years old at the index visit and 2-3 years older at the time of subsequent BMI measurement (median 2.3 years, interquartile range 2.1-2.8 years after the index visit) demonstrated that $71.9 \%$ of children with severe obesity continued to be
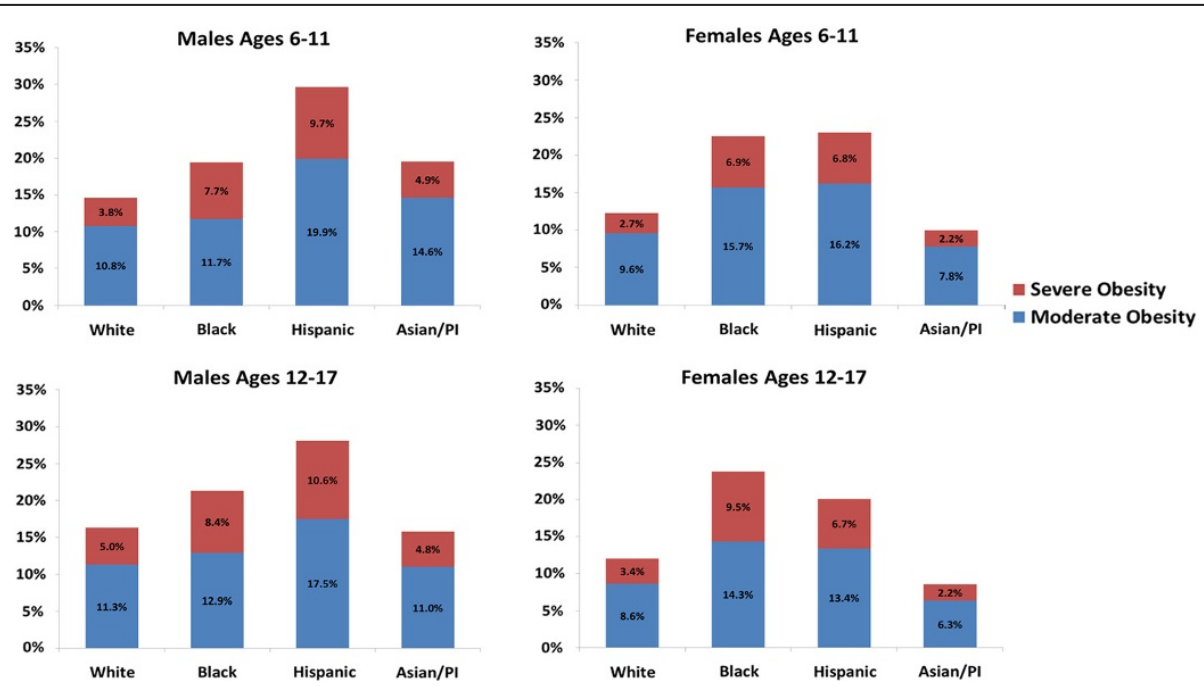

Figure 1 The proportion of children and adolescents with moderate and severe obesity by age, sex and race/ethnicity. Comparisons by race/ethnicity within each age-sex group showed that the prevalence of obesity (BMI $\geq 95^{\text {th }}$ percentile) was significantly different between all racial/ethnic subgroups ( $p<0.01$ ) except for differences in obesity prevalence for black vs Asian 6-11 year old boys $(p=0.90)$, black vs. Hispanic 6-11 year old girls $(p=0.64)$, and white vs. Asian $12-17$ year old boys $(p=0.37)$. The prevalence of severe obesity (BMl $\geq 120 \%$ of the $95^{\text {th }}$ percentile) was also significantly different between all racial/ethnic subgroups ( $p<0.01)$, except for white vs. Asian $(p=0.06)$ and black vs. Hispanic $6-11$ year old girls $(p=0.96)$, and white vs. Asian $12-17$ year old boys $(p=0.58)$. 
Table 2 Characteristics of obese children and adolescents based on percentage of the $95^{\text {th }}$ percentile for body mass index (BMI)

\begin{tabular}{|c|c|c|c|c|c|c|c|}
\hline & $\begin{array}{c}\text { Overall } \\
N=21,013\end{array}$ & $\begin{array}{l}100-109 \% \times 95^{\text {th }} \\
\text { percentile }\end{array}$ & $\begin{array}{c}110-119 \% \times 95^{\text {th }} \\
\text { percentile }\end{array}$ & $\begin{array}{l}\geq 120 \% \times 95^{\text {th }} \\
\text { percentile }\end{array}$ & $\begin{array}{c}120-129 \% \times 95^{\text {th }} \\
\text { percentile }\end{array}$ & $\begin{array}{l}130-139 \% \times 95^{\text {th }} \\
\text { percentile }\end{array}$ & $\begin{array}{l}\geq 140 \% \times 95^{\text {th }} \\
\text { percentile }\end{array}$ \\
\hline OVERALL & 21,013 & 8923 (42.5\%) & $5558(26.5 \%)$ & $6532(31.1 \%)$ & $3172(15.1 \%)$ & 1701 (8.1\%) & 1659 (7.9\%) \\
\hline \multicolumn{8}{|l|}{ Age group } \\
\hline $6-11$ yrs & 9726 & 4314 (44.4\%) & 2639 (27.1\%) & $2773(28.5 \%)$ & $1486(15.3 \%)$ & 702 (7.2\%) & $585(6.0 \%)$ \\
\hline $12-17 y r s$ & 11287 & 4609 (40.8\%) & 2919 (25.9\%) & 3759 (33.3\%) & $1686(14.9 \%)$ & 999 (8.9\%) & 1074 (9.5\%) \\
\hline \multicolumn{8}{|l|}{$\mathrm{BMI}$, mean $\pm \mathrm{SD}$} \\
\hline Age $6-11$ yrs & $25.1 \pm 3.7$ & $22.7 \pm 2.0$ & $25.0 \pm 2.1$ & $29.0 \pm 3.7$ & $27.1 \pm 2.2$ & $29.4 \pm 2.5$ & $33.4 \pm 4.2$ \\
\hline Age $12-17$ yrs & $31.9 \pm 4.9$ & $28.4 \pm 1.7$ & $31.0 \pm 1.9$ & $36.9 \pm 4.8$ & $33.7 \pm 2.0$ & $36.5 \pm 2.1$ & $42.3 \pm 5.0$ \\
\hline BOYS & 12154 & $5032(41.4 \%)$ & 3187 (26.2\%) & 3935 (32.4\%) & 1946 (16.0\%) & 1015 (8.4\%) & 974 (8.0\%) \\
\hline \multicolumn{8}{|l|}{ Age group } \\
\hline $6-11$ yrs & 5662 & 2449 (43.3\%) & 1511 (26.7\%) & 1702 (30.1\%) & 910 (16.1\%) & $426(7.5 \%)$ & $366(6.5 \%)$ \\
\hline $12-17 y r s$ & 6492 & $2583(39.8 \%)$ & 1676 (25.8\%) & 2233 (34.4\%) & $1036(16.0 \%)$ & 589 (9.1\%) & $608(9.4 \%)$ \\
\hline \multicolumn{8}{|l|}{$\mathrm{BMI}$, mean $\pm \mathrm{SD}$} \\
\hline Age $6-11$ yrs & $24.9 \pm 3.6$ & $22.4 \pm 1.9$ & $24.7 \pm 2.0$ & $28.6 \pm 3.6$ & $26.7 \pm 2.1$ & $29.0 \pm 2.3$ & $32.7 \pm 4.1$ \\
\hline Age $12-17$ yrs & $31.4 \pm 4.6$ & $27.8 \pm 1.5$ & $30.4 \pm 1.7$ & $36.1 \pm 4.5$ & $33.2 \pm 1.8$ & $35.9 \pm 2.0$ & $41.5 \pm 4.5$ \\
\hline GIRLS & 8859 & 3891 (43.9\%) & 2371 (26.8\%) & 2597 (29.3\%) & $1226(13.8 \%)$ & $686(7.7 \%)$ & 685 (7.7\%) \\
\hline \multicolumn{8}{|l|}{ Age group } \\
\hline $6-11$ yrs & 4064 & 1865 (45.9\%) & 1128 (27.8\%) & 1071 (26.4\%) & 576 (14.2\%) & $276(6.8 \%)$ & $219(5.4 \%)$ \\
\hline $12-17 y r s$ & 4795 & 2026 (42.3\%) & 1243 (25.9\%) & $1526(31.8 \%)$ & $650(13.6 \%)$ & $410(8.6 \%)$ & 466 (9.7\%) \\
\hline \multicolumn{8}{|l|}{$\mathrm{BMl}$, mean $\pm \mathrm{SD}$} \\
\hline Age $6-11$ yrs & $25.5 \pm 3.8$ & $23.1 \pm 2.1$ & $25.5 \pm 2.2$ & $29.7 \pm 3.9$ & $27.7 \pm 2.4$ & $30.1 \pm 2.6$ & $34.4 \pm 4.2$ \\
\hline Age $12-17$ yrs & $32.6 \pm 5.0$ & $29.0 \pm 1.7$ & $31.8 \pm 1.9$ & $38 . \pm 5.1$ & $34.7 \pm 1.9$ & $37.4 \pm 2.1$ & $43.4 \pm 5.5$ \\
\hline
\end{tabular}

Numbers represent row percentages.

severely obese (with an even greater proportion among younger children) and an additional $24.7 \%$ remained obese but their BMI declined to the moderately obese range (Figure 2D). Among moderately obese children, $10.5 \%$ became severely obese $(14.1 \%$ for children ages $6-7$ ) while $57.1 \%$ remained moderately obese and $26.6 \%$ became overweight but not obese (Figure 2C). Less than one fifth (15.3\%) of overweight children became moderately obese, while half $(51.2 \%)$ remained overweight and one third (33.2\%) had follow-up BMI in the normal range (Figure $2 \mathrm{~B}$ ).

Among obese children, we also examined whether there was a graded relationship between increasing BMI percentage above the $95^{\text {th }}$ percentile and elevated blood pressure. As shown in Table 3, the proportion of children with normal blood pressure fell while those with prehypertension or hypertension increased as BMI percentage increased above the $95^{\text {th }}$ percentile. Adjusting for differences in age, sex and race/ethnicity, a significant graded relationship between obesity severity and hypertension remained, with the adjusted odds of hypertension increasing across increasing BMI strata: OR 1.5 (CI 0.9-2.3) for BMI 110-119\%, OR 1.8 (CI 1.1-3.0) for BMI 120-129\%, OR 3.5 (CI 2.1-5.8) for BMI 130-139\%, and OR 5.7 (CI 3.6-8.9) for BMI $\geq 140 \%$ of the $95^{\text {th }}$ BMI percentile, compared to BMI $100-109 \%$ of the $95^{\text {th }}$ BMI percentile. Severe obesity (BMI $\geq 120 \%$ of the $95^{\text {th }}$ BMI percentile) was associated with a 2.7 -fold increased odds of hypertension compared to those with moderate obesity (BMI $100-119 \%$ of the $95^{\text {th }}$ percentile; adjusted OR 2.7, CI 2.0-3.7). These results were similar when restricting analyses to the subset of 11,705 obese children and adolescents who had three consecutive BP measurements (data not shown).

\section{Discussion}

This study extends results from previously published studies of pediatric obesity by examining gradations in severe obesity by gender, age and race/ethnicity. In addition, we evaluated the persistence of obesity and obesity severity over $2-3$ years, as well as the association between obesity severity and hypertension. Severe obesity was found in $5.6 \%$ of children and adolescents age 6-17 years old, with prevalence highest among children of Hispanic ethnicity or black race, similar to findings for overall obesity (BMI $\geq 95^{\text {th }}$ percentile). National data [7] and other racially and ethnically diverse cohorts [12] also demonstrate a disproportionately higher prevalence 

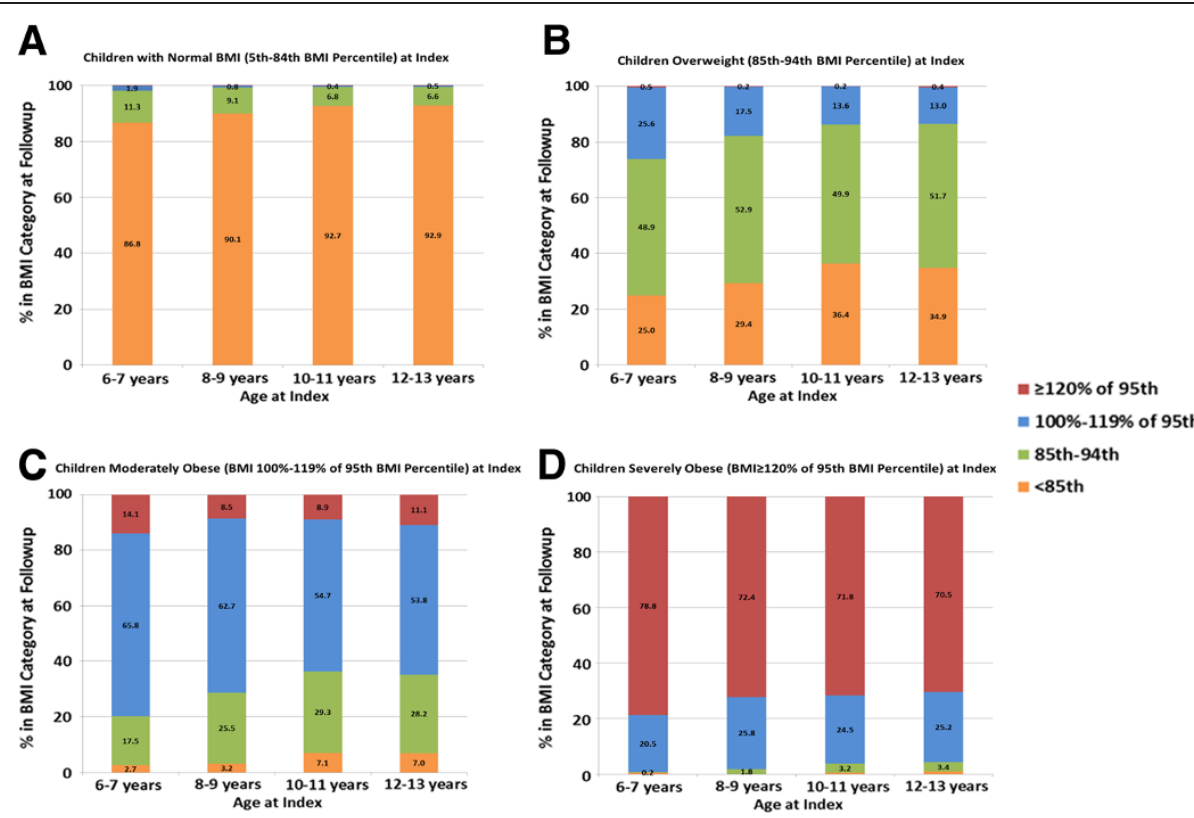

Figure 2 Follow-up BMI category based on BMI percentile and BMI percentage of the $95^{\text {th }}$ percentile by age and BMI at the index visit. (A) For children with normal BMl at the index visit $(N=50,685)$, an increasing proportion of younger children were overweight at 2-3 years of follow-up ( $p<0.001$ comparing 6-7 and 8-9 year olds to 12-13 year olds, with no differences between 10-11 and 12-13 year olds, $p=0.6$ ). (B) For children who were overweight at the index visit $(N=14,057)$, an increasing proportion of younger children were obese at follow-up ( $p<0.001$, test for trend). (C) For children who were moderately obese at the index visit (BMI 100-119\% of the $95^{\text {th }}$ percentile, $N=9848$ ), an increasing proportion of younger children were obese at follow-up ( $<<0.001$, test for trend). The proportions of moderately obese children who remained obese at follow-up were significantly different between all age groups $(p<0.01)$ except for $10-11$ year olds compared to 12-13 year olds. (D) For children who were severely obese at the index visit $(N=4295)$, nearly all were obese or severely obese at follow-up (95.7-99.3\%). Children in the youngest age group (6-7 years old) had the highest prevalence of severe obesity at follow-up compared to other age groups $(p<0.05)$. Differences between the older age groups were not significantly different.

of severe obesity in Hispanic boys and non-Hispanic black girls. Furthermore, longitudinal data on BMI tracking from more than 80,000 children and adolescents included within this study cohort (of whom 9848 were moderately obese and 4295 severely obese at the index visit) demonstrate that severely obese children tend to maintain the same degree of obesity over time, particularly when evident at a young age. These findings support data from other longitudinal pediatric cohorts documenting a strong tracking effect of elevated BMI in childhood, as well as into adulthood [18-23]. Similar shifts in BMI across normal, overweight, obese and severely obese categories were also observed in a multisite school-based study of 3993 U.S. sixth graders re-examined later in eigth grade, where $76 \%$ of severely obese youths (alternatively defined by the $99^{\text {th }}$ BMI percentile) remained severely obese after 2.5 years of follow-up [24].

While previous findings from this source cohort demonstrated that pediatric obesity was significantly related to an increased prevalence of hypertension [13], in this study we applied new obesity stratification criteria and found that the risk of hypertension increased as the degree of obesity increased, with a nearly three-fold greater risk of hypertension among severely obese children compared to moderately obese children. These findings are consistent with the known interrelationship of adiposity, hypertension and cardiometabolic factors in children [5,25-29], supporting evidence of greater risk with extreme or severe obesity [5,30-32], and further quantify the association between obesity severity and hypertension as a representation of cardiovascular health risk. The persistence of severe obesity in longitudinal analyses, supporting data from other pediatric studies examining longitudinal shifts in BMI category among smaller population cohorts [24], also documents an ongoing highly significant adverse cardiovascular impact and emphasizes the need for early weight loss management.

These data have several clinical and public health implications. First, consistent with recently published concensus statements emphasizing the importance of identifying and tracking severe obesity in children and adolescents [10], current approaches to classifying obesity in the clinical setting should be refined at the higher end of the BMI spectrum to more precisely identify those with severe obesity. Categorization based strictly on BMI percentiles does not adequately stratify risk within the extreme BMI 


\begin{tabular}{|c|c|c|c|c|c|}
\hline \multirow[t]{2}{*}{$\mathrm{BMI}>95^{\text {th }}$ percentile } & $\begin{array}{c}\text { Normal blood } \\
\text { pressure (BP) }\end{array}$ & Prehypertension & $\mathrm{BP} \geq 95^{\text {th }}$ percentile & $\begin{array}{c}\text { Confirmed } \\
\text { hypertension }\end{array}$ & $\begin{array}{l}\text { Adjusted odds } \\
\text { of hypertension }\end{array}$ \\
\hline & $N=12802$ & $N=5308$ & $N=2796$ & $N=166$ & OR $(95 \% \mathrm{Cl})^{\dagger}$ \\
\hline $100-109 \% \times 95^{\text {th }}$ percentile & 5976 (67.2\%) & $2012(22.6 \%)$ & $903(10.2 \%)$ & $40(0.5 \%)$ & - \\
\hline $110-119 \% \times 95^{\text {th }}$ percentile & 3478 (62.9\%) & $1390(25.2 \%)$ & $659(11.9 \%)$ & $36(0.7 \%)$ & $1.5(0.9-2.3)$ \\
\hline $120-129 \% \times 95^{\text {th }}$ percentile & 1789 (56.8\%) & $866(27.5 \%)$ & $497(15.8 \%)$ & $24(0.8 \%)$ & $1.8(1.1-3.0)$ \\
\hline $130-139 \% \times 95^{\text {th }}$ percentile & 837 (49.5\%) & $515(30.5 \%)$ & $339(20.1 \%)$ & $26(1.5 \%)$ & $3.5(2.1-5.8)$ \\
\hline$\geq 140 \% \times 95^{\text {th }}$ percentile & $722(43.9 \%)$ & $525(31.9 \%)$ & $398(24.2 \%)$ & $40(2.4 \%)$ & $5.7(3.6-8.9)$ \\
\hline
\end{tabular}

row percentages.

${ }^{*}$ For those with an index $\mathrm{BP} \geq 95^{\text {th }}$ percentile, up to 3 consecutive measurements were used to assign final BP status. Hypertension was defined by 3 consecutive $\mathrm{BP} \geq 95^{\text {th }}$ percentile (or SBP $\geq 140 \mathrm{mmHg}$ and/or DBP $\geq 90 \mathrm{mmHg}$ for subsequent BP at age $\geq 18$ years of age). Within this subgroup, there were 1900 (67.9\%) children and adolescents with repeat $\mathrm{BP}<95^{\text {th }}$ percentile and $730(26.1 \%)$ with no subsequent BP available for final assignment.

${ }^{\dagger}$ Odds ratio $(\mathrm{OR})$ and $95 \%$ confidence intervals $(\mathrm{Cl})$, adjusted for differences in age, sex and race/ethnicity.

range ( $>99^{\text {th }}$ percentile). In addition, conventional growth charts have a BMI limit of $36-37 \mathrm{~kg} / \mathrm{m}^{2}$, which is problematic for tracking of weight status in adolescents with extremely high BMI [11]. In this study, we found that classifying obesity severity based on BMI percentage of the $95^{\text {th }}$ percentile, as previously proposed by others $[9,11]$, has the advantage of more precisely categorizing extremely obese individuals for both clinical tracking and research purposes. More importantly, our data demonstrate that this new obesity classification system results in clinically relevant thresholds of higher order obesity associated with graded health risk, as defined by hypertension.

Several factors may constrain the interpretation of our data. First, these data were limited to a subset of children receiving well-child care in a northern California healthcare delivery system and thus may not be fully representative of other population demographics or regions. Second, there is the theoretical possibility that growth chart reference data may differ by age, with implications for examining longitudinal trends. However, our BMI thresholds focus on well-established reference data for the $85^{\text {th }}$ and $95^{\text {th }}$ BMI percentiles thresholds, deriving higher order obesity based on the $95^{\text {th }}$ percentile rather than the $97^{\text {th }}$ or $99^{\text {th }}$ BMI percentiles. Third, while we believe the measurements of BP in these subjects were accurate, assessment of BP in extremely obese children is a challenge due to limitations in cuff size $[26,33,34]$. Finally, we limited our cardiovascular risk assessment to blood pressure, since lipid measurements were not uniformly available to further estimate cardiovascular risk in addition to blood pressure. As such, we believe that the previously documented tracking effect for blood pressure in this age range to adulthood [17] supports the use of hypertension as an important component of overall cardiovascular risk.

In summary, among the substantial number of children with obesity (BMI at or above the $95^{\text {th }}$ percentile), identifying subsets of those with more extreme obesity is of clinical importance. Stratification of obesity by percentage above the $95^{\text {th }}$ BMI percentile shows a graded increased risk of hypertension and may be related to increased risk of other cardiovascular risk factors such as dyslipidemia and prediabetes. A more refined and precise classification of severe pediatric obesity using contemporary criteria [10] may serve to improve clinical practice, tracking, as well as public health surveillance, and facilitate research on the best approaches to managing cardiovascular risk in these subgroups of varying obesity severity.

\section{Competing interests}

The authors declare that they have no competing interests.

\section{Authors' contributions}

$J \mathrm{~L}, \mathrm{SD}, \mathrm{AS}$ and LG conceptualized and designed the study. MC conducted the data analyses. JL, LG, BM, AS and RP drafted the initial manuscript. All authors (JL, MC, AS, SD, RP, BM, EP, NS, MD, EK, KA, DM, PO, LG) provided critical input on data analysis and interpretation, revised the manuscript for important intellectual content and approved the final version.

\section{Acknowledgements}

The authors would like to thank Joel Gonzalez, Jena Joy MD and Gabriela Sanchez for assistance with literature review and manuscript preparation. This study was funded by the National Heart, Lung and Blood Institute at the National Institutes of Health 1RO1HL093345 to HealthPartners Research Foundation (Patrick O'Connor, Principal Investigator) and conducted within the Cardiovascular Research Network, a consortium of research organizations affiliated with the HMO Research Network and sponsored by the National Heart Lung and Blood Institute (U19 HL91179-01).

\section{Author details}

${ }^{1}$ Division of Research, Kaiser Permanente Northern California, 2000 Broadway, Oakland, CA 94612, USA. ²Department of Medicine, Kaiser Permanente Oakland Medical Center, Oakland, CA, USA. ${ }^{3}$ Department of Pediatrics, University of Minnesota, Minneapolis, MN, USA. ${ }^{4}$ University of Colorado Denver School of Medicine, Denver, CO, USA. ${ }^{5}$ Division of Public Health Sciences, Wake Forest University School of Medicine, Winston-Salem, NC, USA. ${ }^{6}$ HealthPartners Institute for Education and Research, Minneapolis, MN, USA. ${ }^{7}$ Institute for Health Research, Kaiser Permanente Colorado, Denver, CO, USA. ${ }^{8}$ Department of Pediatrics, Kaiser Permanente San Francisco Medical Center, San Francisco, CA, USA.

Received: 23 October 2013 Accepted: 15 February 2014 Published: 3 March 2014 


\section{References}

1. Ogden $\mathrm{CL}$, Carroll MD: Prevalence of Obesity Among Children and Adolescents: United States, Trends 1963-1965 Through 2007-2008 In National Center for Health Statistics E-Stat; 2010. Available from: http://www.cdc.gov/nchs/data/hestat/obesity_child_07_08/obesity_ child_07_08.pdf.

2. Ogden $\mathrm{CL}$, Carroll MD, Kit BK, Flegal KM: Prevalence of obesity and trends in body mass index among US children and adolescents, 1999-2010. JAMA 2012, 307:483-490.

3. Ogden $\mathrm{CL}$, Flegal KM: Changes in terminology for childhood overweight and obesity. Natl Health Stat Report 2010, 25:1-5.

4. Barlow SE: Expert committee recommendations regarding the prevention, assessment, and treatment of child and adolescent overweight and obesity: summary report. Pediatrics 2007, 120(Suppl 4):S164-S192.

5. Freedman DS, Mei Z, Srinivasan SR, Berenson GS, Dietz WH: Cardiovascular risk factors and excess adiposity among overweight children and adolescents: the Bogalusa Heart Study. J Pediatr 2007, 150:12-17. e12.

6. Skelton JA, Cook SR, Auinger P, Klein JD, Barlow SE: Prevalence and trends of severe obesity among US children and adolescents. Acad Pediatr 2009, 9:322-329.

7. Wang YC, Gortmaker SL, Taveras EM: Trends and racial/ethnic disparities in severe obesity among US children and adolescents, 1976-2006. Int J Pediatr Obes 2011, 6:12-20.

8. Woo JG: Using body mass index Z-score among severely obese adolescents: a cautionary note. Int J Pediatr Obes 2009, 4:405-410.

9. Flegal KM, Wei R, Ogden CL, Freedman DS, Johnson CL, Curtin LR: Characterizing extreme values of body mass index-for-age by using the 2000 centers for disease control and prevention growth charts. Am J Clin Nutr 2009, 90:1314-1320.

10. Kelly AS, Barlow SE, Rao G, Inge TH, Hayman LL, Steinberger J, Urbina EM, Ewing $\sqcup$, Daniels SR: Severe obesity in children and adolescents: identification, associated health risks, and treatment approaches: a scientific statement from the american heart association. Circulation 2013, 128:1689-1712.

11. Gulati AK, Kaplan DW, Daniels SR: Clinical tracking of severely obese children: a new growth chart. Pediatrics 2012, 130:1136-1140.

12. Koebnick C, Smith N, Coleman KJ, Getahun D, Reynolds K, Quinn VP, Porter AH, Der-Sarkissian JK, Jacobsen SJ: Prevalence of extreme obesity in a multiethnic cohort of children and adolescents. J Pediatr 2010, 157:26-31. e22.

13. Lo JC, Sinaiko A, Chandra M, Daley MF, Greenspan LC, Parker ED, Kharbanda EO, Margolis KL, Adams K, Prineas R, Magid D, O'Connor PJ: Prehypertension and hypertension in community-based pediatric practice. Pediatrics 2013, 131:e415-e424.

14. A SAS Program for the 2000 CDC Growth Charts (ages 0 to $<20 \mathrm{y}$ ). [http://www.cdc.gov/nccdphp/dnpao/growthcharts/resources/sas.htm]

15. Lo JC, Maring B, Chandra M, Daniels SR, Sinaiko A, Daley MF, Sherwood NE, Kharbanda EO, Parker ED, Adams KF, Prineas RJ, Magid DJ, O'Connor PJ, Greenspan LC: Prevalence of obesity and extreme obesity in children aged 3-5 years. Pediatric Obesity 2013.

16. Cut-offs to define outliers in the 2000 CDC Growth Charts. [http://www. cdc.gov/nccdphp/dnpa/growthcharts/resources/BIV-cutoffs.pdf]

17. National High Blood Pressure Education Program Working Group on High Blood Pressure in Children and Adolescents: The fourth report on the diagnosis, evaluation, and treatment of high blood pressure in children and adolescents. Pediatrics 2004, 114:555-576.

18. Biro FM, Huang B, Morrison JA, Horn PS, Daniels SR: Body mass index and waist-to-height changes during teen years in girls are influenced by childhood body mass index. J Adolesc Health 2010, 46:245-250.

19. Thompson DR, Obarzanek E, Franko DL, Barton BA, Morrison J, Biro FM, Daniels SR, Striegel-Moore RH: Childhood overweight and cardiovascular disease risk factors: the National Heart, Lung, and Blood Institute Growth and Health Study. J Pediatr 2007, 150:18-25.

20. Kvaavik E, Tell GS, Klepp KI: Predictors and tracking of body mass index from adolescence into adulthood: follow-up of 18 to 20 years in the Oslo Youth Study. Arch Pediatr Adolesc Med 2003, 157:1212-1218.

21. Whitaker RC, Wright JA, Pepe MS, Seidel KD, Dietz WH: Predicting obesity in young adulthood from childhood and parental obesity. $N$ Engl J Med 1997, 337:869-873.

22. Guo SS, Wu W, Chumlea WC, Roche AF: Predicting overweight and obesity in adulthood from body mass index values in childhood and adolescence. Am J Clin Nutr 2002, 76:653-658.
23. Morrison JA, Glueck CJ, Daniels SR, Wang P: Race, childhood insulin, childhood caloric intake, and class 3 obesity at age 24: 14-year prospective study of schoolgirls. Obesity (Silver Spring) 2012, 20:597-604.

24. Marcus MD, Foster GD, El Ghormli L, Baranowski T, Goldberg L, Jago R, Linder B, Steckler A, Trevino R: Shifts in BMI category and associated cardiometabolic risk: prospective results from HEALTHY study. Pediatrics 2012, 129:e983-e991.

25. Charakida M, Jones A, Falaschetti E, Khan T, Finer N, Sattar N, Hingorani A, Lawlor DA, Smith GD, Deanfield JE: Childhood obesity and vascular phenotypes: a population study. J Am Coll Cardiol 2012, 60:2643-2650.

26. Sorof J, Daniels $\mathrm{S}$ : Obesity hypertension in children: a problem of epidemic proportions. Hypertension 2002, 40:441-447.

27. Sorof JM, Poffenbarger T, Franco K, Bernard L, Portman RJ: Isolated systolic hypertension, obesity, and hyperkinetic hemodynamic states in children. J Pediatr 2002, 140:660-666.

28. Flynn J: The changing face of pediatric hypertension in the era of the childhood obesity epidemic. Pediatr Nephrol 2013, 28:1059-1066.

29. Tu W, Eckert GJ, DiMeglio LA, Yu Z, Jung J, Pratt JH: Intensified effect of adiposity on blood pressure in overweight and obese children. Hypertension 2011, 58:818-824.

30. Ice CL, Murphy E, Cottrell L, Neal WA: Morbidly obese diagnosis as an indicator of cardiovascular disease risk in children: results from the CARDIAC Project. Int J Pediatr Obes 2011, 6:113-119.

31. Valerio G, Maffeis C, Balsamo A, Del Giudice EM, Brufani C, Grugni G, Licenziati MR, Brambilla P, Manco M: Severe obesity and cardiometabolic risk in children: comparison from two international classification systems. PloS One 2013, 8:e83793.

32. Marcus MD, Baranowski T, DeBar LL, Edelstein S, Kaufman FR, Schneider M, Siega-Riz AM, Staten MA, Virus A, Yin Z: Severe obesity and selected risk factors in a sixth grade multiracial cohort: the HEALTHY study. J Adolesc Health 2010, 47:604-607.

33. Gomez-Marin O, Prineas RJ, Rastam L: Cuff bladder width and blood pressure measurement in children and adolescents. J Hypertens 1992, 10:1235-1241

34. Whincup PH, Cook DG, Shaper AG: Blood pressure measurement in children: the importance of cuff bladder size. J Hypertens 1989, 7:845-850.

\section{doi:10.1186/1687-9856-2014-3}

Cite this article as: Lo et al: Severe obesity in children: prevalence, persistence and relation to hypertension. International Journal of Pediatric Endocrinology 2014 2014:3.

\section{Submit your next manuscript to BioMed Central and take full advantage of:}

- Convenient online submission

- Thorough peer review

- No space constraints or color figure charges

- Immediate publication on acceptance

- Inclusion in PubMed, CAS, Scopus and Google Scholar

- Research which is freely available for redistribution 